\title{
Use of Sacubitril/valsartan in patients with cardio toxicity and heart failure due to chemotherapy
}

Vanesa Gregorietti ${ }^{1}$, Teresa Lopez Fernandez ${ }^{2}$, Diego Costa ${ }^{1}$, Elías Ortega Chahla ${ }^{1}$ and Andrés J. Daniele ${ }^{1 *}$

\begin{abstract}
Background: Cancer therapy-related cardiac dysfunction (CTRCD) is a critical problem with an impact on both oncological and cardiovascular prognosis, especially when it prevents patients from receiving cancer treatment. Standard therapy for heart failure (HF) is recommended for CTRCD, but there is no well-established evidence on how sacubitril/valsartan may help cancer patients with cardiotoxicity.
\end{abstract}

Objectives: The aim of this trial was to study the effectiveness of sacubitril-valsartan in patients with CTRCD treated in cardio-oncology units.

Methods: We enrolled 635 patients with breast cancer and followed them with echocardiography and NT- proBNP. Patients who developed left ventricular dysfunction and heart failure were treated with angiotensin-converting enzyme inhibitors (ACEI) (enalapril) or angiotensin receptor blockers (ARB) (valsartan), aldosterone antagonists (eplerenone), digitalis and diuretics (furosemide), as needed. When patients remained symptomatic and met the PARADIGM-HF inclusion criteria, sacubitril/valsartan was started instead of enalapril or valsartan.

We analyzed clinical, laboratory and echocardiographic variables to determine the beneficial effects of sacubitril/ valsartan on left ventricular remodeling (improvement of left ventricular ejection fraction (LVEF), left ventricle internal diameter in diastole), diastolic dysfunction (E/e' ratio), reduction in NT-proBNP levels, New York Heart Association (NHYA) class and improvement in the 6-min walk test.

Also, we analyzed serum creatinine and potassium levels to determine treatmentsafety in this population. Median follow-up was 20 months.

Results: Twenty-eight patients developed cardiotoxicity and were treated with sacubitril/valsartan. The sacubitril/ valsartan dose was $100 \mathrm{mg}$ (sacubitril $49 \mathrm{mg} /$ valsartan $51 \mathrm{mg}$ ) in 12 patients (42.85\%) and $200 \mathrm{mg}$ (sacubitril $97 \mathrm{mg}$ / valsartan $103 \mathrm{mg}$ ) in 16 patients (57.15\%). No deaths were reported, and one patient underwent heart transplantation.

Baseline median NT-proBNP was $997.5 \mathrm{pg} / \mathrm{ml}$ (IQR 663.8 - 2380.8), which decreased to a median of $416.5 \mathrm{pg} / \mathrm{ml}$ (IQR 192.0-798.2) on follow-up with $p<0.001$.

Baseline NYHA functional class was III (78.6\%) or IV (21.4\%), and it improved to I (57.1\%) or II (42.9\%) on follow-up. LVEF increased with treatment from $26.7 \pm 5.4 \%$ to $32.3 \pm 5.5 \%(p<0.001)$. There were also significant improvements in left (Continued on next page)

\footnotetext{
*Correspondence: ajdaniele@gmail.com

${ }^{1}$ Cardio-Oncology Department, Roffo Institute, 5481 Av San Martin. CABA, Buenos Aires, Argentina

Full list of author information is available at the end of the article
}

(c) The Author(s). 2020 Open Access This article is licensed under a Creative Commons Attribution 4.0 International License, which permits use, sharing, adaptation, distribution and reproduction in any medium or format, as long as you give appropriate credit to the original author(s) and the source, provide a link to the Creative Commons licence, and indicate if changes were made. The images or other third party material in this article are included in the article's Creative Commons licence, unless indicated otherwise in a credit line to the material. If material is not included in the article's Creative Commons licence and your intended use is not permitted by statutory regulation or exceeds the permitted use, you will need to obtain permission directly from the copyright holder. To view a copy of this licence, visit http://creativecommons.org/licenses/by/4.0/ The Creative Commons Public Domain Dedication waiver (http://creativecommons.org/publicdomain/zero/1.0/) applies to the data made available in this article, unless otherwise stated in a credit line to the data. 
(Continued from previous page)

ventricle internal diameter in diastole (LVIDD), diastolic function, 6-min walk test, and mitral valve regurgitation. There were no differences between basal and follow-up levels of serum creatinine or potassium.

Conclusion: Sacubitril/valsartan might be a promising treatment option in patients with refractory CTRCD.

Keywords: Heart failure, Cancer, Cardiotoxicity, Sacubitril/valsartan

\section{Background}

Heart failure is defined as a constellation of symptoms and signs that are attributed to the inability of the heart to produce a cardiac output meeting body demands. Despite advances in treatment, it is still a life-threatening disease, affecting between 1 and $2 \%$ of the population, and is more commonly seen in the elderly, with a prevalence of $6-10 \%$ of patients over 65 years [1]. There are different causes of heart failure, and one of them is cancer therapy-related cardiac dysfunction (CTRCD).

CTRCD poses an obstacle in the treatment of cancer patients and is a serious problem for the healthcare system. Its incidence varies according to the cancer therapy analyzed. Classically CTRCD was described as secondary to anthracycline therapy but currently, various oncology therapies (anti HER2, tyrosine kinase inhibitors, proteasome inhibitors) are potential causes [2].

Standard pharmacological therapies indicated for the treatment of HF have been shown to be also useful in CTRCD.

Sacubitril/valsartan (LCZ-696) is a combined neprilysin inhibitor and angiotensin AT1 receptor blocker approved in recent years for the treatment of chronic heart failure with reduced ejection fraction. The PARADIGMHF study was the trial that led to the approval of the use of sacubitril/valsartan for the treatment of HF [3]. In the PARADIGM-HF study, the subgroup of patients with CTRCD was not evaluated. In an area where there have been limited pharmacological advances in the last 10 years, this drug was a game-changer.

The optimal use of sacubitril/valsartan in clinical practice needs further investigation, in particular for patients with CTRCD as they are usually poorly represented in clinical trials. This trial is the first prospective study that attempts to demonstrate the usefulness of sacubitril/valsartan in the treatment of CTRCD.

\section{Methods}

635 consecutive patients with a history of breast cancer who received treatment with chemotherapy and were referred from the Cardio-oncology Department were enrolled prospectively from June 2016 to January 2018.

Cardiovascular evaluation was clinically performed using echocardiography and complete biochemical work-up (including NT-proBNP) at baseline and during treatment for up to 24 months. Patients receiving anthracyclines were followed using the Mayo Clinic protocol [4] and in those treated with anti-HER2 therapies, an echocardiography was performed every 3 months.

We define CTRCD as a reduction in left ventricular ejection fraction (LVEF) of more than 10\% from baseline to a $\mathrm{LVEF}<53 \%$ [5]. We did not have access to strain imaging echocardiography.

The patients who developed cardiotoxicity were treated with beta-blockers (carvedilol), angiotensin-converting enzyme inhibitors (enalapril) or angiotensin receptor blockers (valsartan), aldosterone antagonist (eplerenone) digitalis and diuretics (furosemide) as needed. When patients remained symptomatic and met the PARADIGM-HF inclusion criteria, sacubitril/valsartan was started instead of enalapril or valsartan.

All patients started with a dose of $100 \mathrm{mg}$ (sacubitril $49 \mathrm{mg} / \mathrm{valsartan} 51 \mathrm{mg}$ ) per day and adjustments were performed gradually according to tolerance.

We analyzed clinical, laboratory and echocardiographic variables to determine the beneficial effects of sacubitril/ valsartan on left ventricular remodeling (improvement of LVEF, left ventricle internal diameter in diastole), diastolic dysfunction (E/e' ratio), reduction in NT-proBNP levels, New York Heart Association (NYHA) class and improvement in the 6-min walk test.

Also, we analyzed serum creatinine and potassium levels to determine the treatment's safety in this population.

\section{Statistical analysis}

Continuous variables were summarized as means \pm standard deviations (SD) or medians with interquartile ranges (IQR) and compared with Student's t-test or Wilcoxon's test for paired samples, according to their distribution. Categorical values were expressed as percentages and compared with the chi-squared test. Finally, correlations were assessed with Pearson's correlation coefficient (PCC). Statistical significance was considered with a $p$ value of less than 0.05 . All analyses were performed with $\mathrm{R}$ version 3.6.1.

\section{Results}

Fifty-one patients developed CTRCD; 28 patients were available for analysis because they met the inclusion criteria. Most of them were women treated for breast 
cancer with doxorubicin/cyclophosphamide or trastuzumab/pertuzumab.

There was no difference in the cumulative dose of doxorubicin among patients receiving sacubitril/valsartan or not.

The baseline characteristics are outlined in Table 1. The median time from the start of anti-cancer therapy to the occurrence of heart failure with reduced ejection fraction (HFrEF) was 183.6 \pm 95.4 days and the median time from HFrEF to sacubitril/valsartan initiation was $48.4 \pm 12.3$ days.

Table 1 Population baseline characteristics

\begin{tabular}{|c|c|}
\hline Characteristic $(n=28)$ & Mean \pm SD or $n(\%)$ \\
\hline Age (years) & $56.2 \pm 13.4$ \\
\hline Females & 25 (89.3\%) \\
\hline BP & $14(50 \%)$ \\
\hline Smoker & $12(42.86 \%)$ \\
\hline Hypercholesterolemia & $10(35.71 \%)$ \\
\hline Diabetes Mellitus & $8(28.57 \%)$ \\
\hline History of ischemic cardiac disease & $2(7.14 \%)$ \\
\hline Left Breast Cancer & $18(64.3 \%)$ \\
\hline Radiotherapy & $9(32.1 \%)$ \\
\hline Ejection fraction (\%) & $26.68(5.35)$ \\
\hline Creatinine (mg/dl) & $1.31 \pm 0.16$ \\
\hline \multicolumn{2}{|l|}{ NYHA functional classification } \\
\hline । & $0(0 \%)$ \\
\hline$\|$ & $0(0 \%)$ \\
\hline$\|$ & $22(78.6 \%)$ \\
\hline IV & $6(21.4 \%)$ \\
\hline \multicolumn{2}{|l|}{ Chemotherapy } \\
\hline Doxorubicin & $23(82.1 \%)$ \\
\hline Cyclophosphamide & $23(82.1 \%)$ \\
\hline Docetaxel & $3(10.7 \%)$ \\
\hline Trastuzumab & $8(28.6 \%)$ \\
\hline Pertuzumab & $4(14.3 \%)$ \\
\hline Days since chemotherapy started & $183.6 \pm 95.4$ \\
\hline \multicolumn{2}{|l|}{ Heart Failure treatment at enrollment } \\
\hline Beta Blockers & $26(92,85 \%)$ \\
\hline ACEI & $12(42.85 \%)$ \\
\hline ARB & $13(46.43 \%)$ \\
\hline Digitalis & $9(32.14 \%)$ \\
\hline Mineralocorticoids antagonist & $18(64.28 \%)$ \\
\hline Diuretics & $20(71.43 \%)$ \\
\hline ICD & $3(10.71 \%)$ \\
\hline CRT-D & $2(7.14 \%)$ \\
\hline Heart transplant & $1(3.6 \%)$ \\
\hline
\end{tabular}

The dose of sacubitril/valsartan was $100 \mathrm{mg}$ (sacubitril $49 \mathrm{mg} / \mathrm{valsartan} 51 \mathrm{mg}$ ) in 12 patients $(42.85 \%)$ and 200 mg (sacubitril $97 \mathrm{mg} /$ valsartan $103 \mathrm{mg}$ ) in 16 patients (57.15\%). One patient received a heart transplant; three, an implantable cardioverter defibrillator, two underwent cardiac resynchronization therapy, and no deaths were reported.

Baseline median NT-proBNP was $997.5 \mathrm{pg} / \mathrm{ml}$ (IQR 663.8-2380.8). On follow-up, it decreased to a median of $416.5 \mathrm{pg} / \mathrm{ml}$ (IQR 192.0-798.2), with $p=0.0039$. Baseline median 6-min walk test was $300 \mathrm{~m}$ (IQR 244.5332.5), and it increased on follow-up to $410 \mathrm{~m}$ (IQR 362.5-440.5), with $p<0.001$ (Fig. 1).

When comparing NYHA functional class, the patients were all in class III $(78.6 \%)$ or IV $(21.4 \%)$ on baseline, and I (57.1\%) or II (42.9\%) on follow-up, as seen in Fig. 2. Similar results were obtained when comparing chemotherapy subgroups and considering the time since chemotherapy was started.

When assessing echocardiographic parameters, we found that ejection fraction improved with treatment from $26.7 \pm 5.4 \%$ to $32.3 \pm 5.5 \%(p<0.001)$. Additionally, baseline left ventricle internal diameter in diastole (LVIDD) was $67.5 \mathrm{~mm}(65.00-69.25)$ and went down to $60 \mathrm{~mm}(59.00-61.25)$ after treatment $(p<0.001)$. Diastolic function, as assessed with the ratio between early mitral inflow velocity and mitral annular early diastolic velocity $\left(E / e^{\prime}\right)$ with a cut-off of 15 , was reduced from $75 \%$ before treatment to $42.9 \%$ after treatment ( $p=$ 0.027). Mitral regurgitation also improved, from a baseline of $21.4 \%$ mild, $60.7 \%$ moderate, and $17.9 \%$ severe, to values after treatment of $67.9,32.1$, and $0.0 \%$, respectively.

There was a negative and significant negative correlation between the decrease in NT-proBNP levels over time and basal ejection fraction $(\mathrm{PCC}=-0.44, \mathrm{p} 0.019)$. As evidenced in Fig. 3, the impact on NT-proBNP levels seems to be higher in patients with lower baseline ejection fraction.

There was no difference between basal and follow up levels of creatinine $(1.31 \pm 0.16 \mathrm{mg} / \mathrm{dl}$ vs $1.34 \pm 0.17 \mathrm{mg} /$ $\mathrm{dl}, p=\mathrm{ns})$ or potassium serum $(4.1 \pm 0.3 \mathrm{mEq} / \mathrm{l}$ vs $4 \pm$ $0.2 \mathrm{mEq} / \mathrm{l}, p=\mathrm{ns})$.

\section{Discussion}

Cardiovascular disease accounts for between 30 and 40\% of global mortality in the general population. Heart failure, the final stage of many cardiovascular conditions, is one of the most common causes of morbidity and mortality, representing about $62 \%$ of the global cardiovascular deaths, and is growing daily [6].

In the oncological population, ventricular dysfunction and heart failure cause significant limitations in 

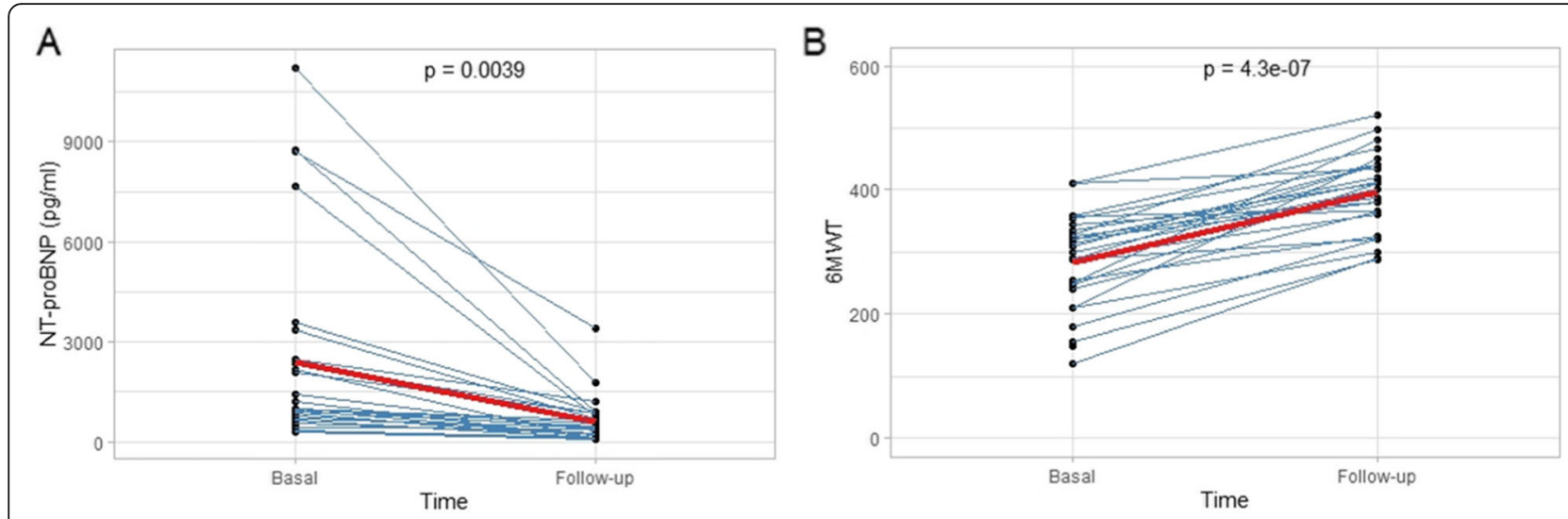

Fig. 1 NT-proBNP levels and 6-min walk test change over time. a: NT-proBNP individual values and mean change over time. b: 6-min walk test (6MWT) individual values and mean change over time

treatment strategies and therefore have a considerable impact on prognosis.

Since the publication of the PARADIGM-HF study, sacubitril/valsartan has been a useful tool for the treatment of patients with ventricular dysfunction and heart failure [3].

Some studies showed improvement of the NYHA class and 6-min walk test with sacubitril/valsartan in patients with HF of etiologies other than CTRCD [7]. Improvement in functional mitral insufficiency after initiation of treatment with sacubitril/valsartan has also been reported $[8,9]$.

None of these studies included patients with cancer and CTRCD, so its usefulness in this group has now become a question to be answered. Several reports on the use of sacubitril/valsartan in CTRCD have been published in recent years. Many of them constitute case reports [10-12]. In recent years some abstracts have been presented at international congresses evaluating the benefit of sacubitril/valsartan in cancer patients.

The importance of oncological patients completing their specific therapy creates the need to improve the treatment of heart failure in this subgroup of patients in order to meet this goal $[13,14]$.

Based on these data we conducted our study, the first prospective trial to determine the usefulness of the sacubitril/valsartan in the treatment of CTRCD.

Our study showed that sacubitril/valsartan therapy in patients with CTRCD produces an improvement in ventricular remodeling (recovery of LVEF and ventricular

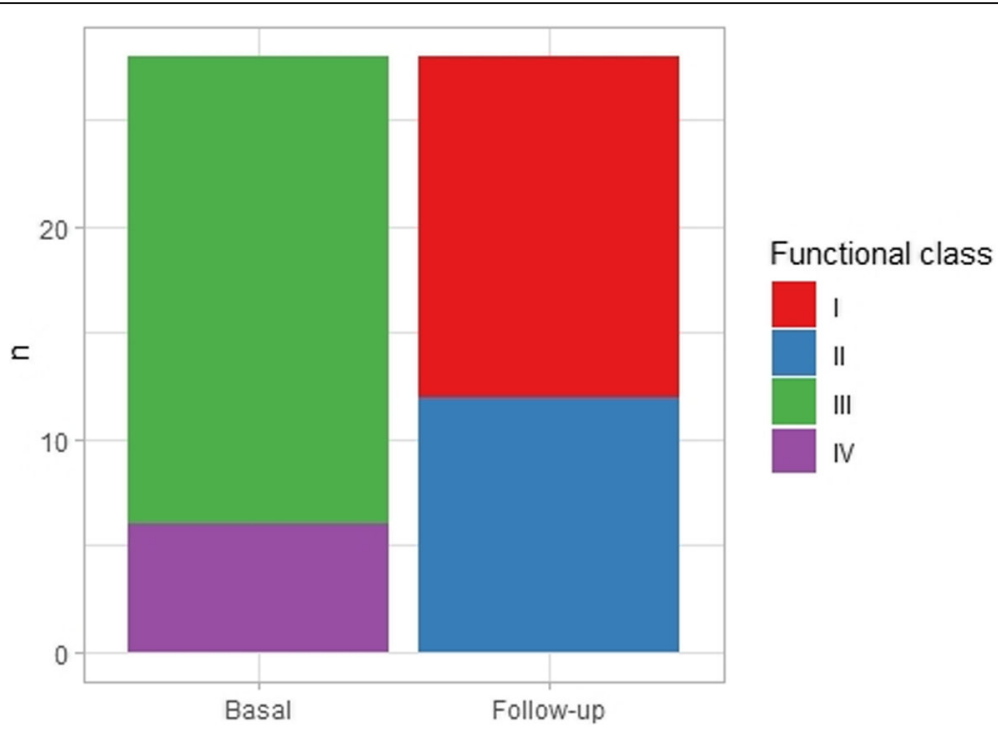

Fig. 2 NYHA functional class change over time 


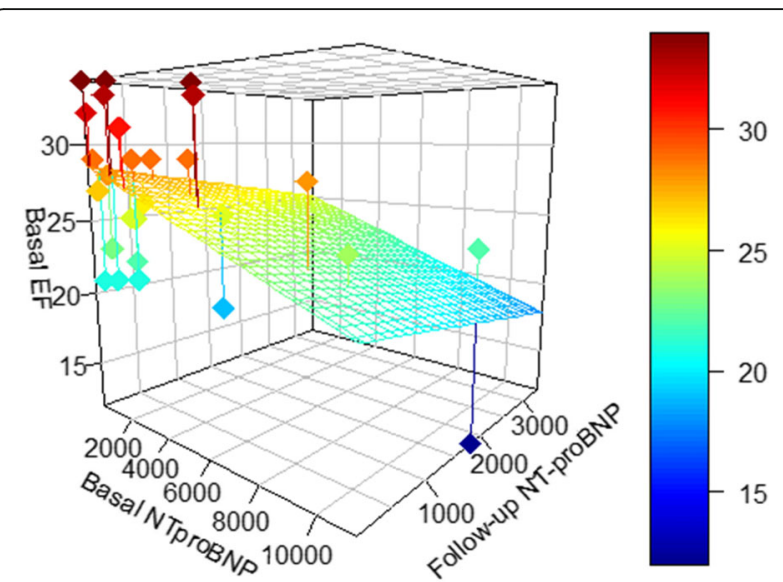

Fig. 3 Correlation between NT-proBNP decrease in $\mathrm{pg} / \mathrm{ml}$ and baseline ejection fraction (EF) in \%

diameters), diastolic dysfunction (E/e' ratio), and of the symptoms reflected in the NYHA class and the 6-min walk test.

Although we identified a difference between patients who received CRT-D and those who did not, due to the small size of the sample, it was not statistically significant.

On the other hand, the analysis of plasma creatinine levels, glomerular filtration rate, and plasma potassium levels showed that in this type of patients, with their co-existing comorbidities, the use of sacubitril/valsartan is safe.

The evidence suggests that sacubitril/valsartan is a valid option in the treatment of CTRCD patients, but a multicenter study with a larger number of patients would be needed to reach more definitive conclusions.

\section{Conclusion}

Sacubitril/valsartan has shown a good safety profile with excellent follow-up results in patients with refractory left ventricular dysfunction related to chemotherapy, which is a promising option in this patient population.

\section{Limitations of investigation}

The use of sacubitril/valsartan seems promising according to the evidence in this limited group of patients, but a large-scale study should be carried out with a larger number of patients to prove the real usefulness of this drug in cardiac failure with ventricular dysfunction due to cardiotoxicity secondary to chemotherapy.

\section{Competencies in medical knowledge}

In breast cancer patients with ventricular dysfunction associated with cardiotoxicity and refractory heart failure, the use of sacubitril-valsartan has proven to be an excellent treatment option in this specific population.

\section{Translational outlook}

More research is needed with a larger number of patients with ventricular dysfunction and heart failure due to cardiotoxicity to evaluate the usefulness of sacubitrilvalsartan in this particular group of patients.

\section{Abbreviations}

CTRCD: Cancer Treatment Caiac Dysfunction; HF: Heart Failure; HFrEF: Heart Failure reduced Ejection Fraction; ACEl: Angiotensin-converting enzyme inhibitors; ARB: Angiotensin receptor blockers; LVEF: Left Ventricular Ejection Fraction; NYHA: New York Heart Association; LVIDD: Left Ventricular Internal Diameter in Diastole

\section{Acknowledgements \\ Not Applicable.}

\section{Authors' contributions}

The authors worked together in the review. The author(s) read and approved the final manuscript.

\section{Funding}

The authors declare that they do not have fundings.

\section{Availability of data and materials} Not applicable.

Ethics approval and consent to participate

Not applicable.

\section{Consent for publication}

Not applicable.

\section{Competing interests}

The authors declare that they have no competing interests.

\section{Author details}

${ }^{1}$ Cardio-Oncology Department, Roffo Institute, 5481 Av San Martin. CABA Buenos Aires, Argentina. ${ }^{2}$ Cardiology Department, La Paz University Hospital, Madrid, Spain.

Received: 4 May 2020 Accepted: 23 September 2020

Published online: 05 November 2020

\section{References}

1. Ponikowski P, Voors AA, Anker SD, Bueno H, Cleland JGF, Coats AJS, et al. 2016 ESC guidelines for the diagnosis and treatment of acute and chronic heart failure. Eur J Heart Fail. 2016;18(8):891-975.

2. Zamorano J, Lancellotti P, et al. 2016 ESC Position Paper on cancer treatments and cardiovascular toxicity developed under the auspices of the ESC Committee for Practice Guidelines: The Task Force for cancer treatments and cardiovascular toxicity of the European Society of Cardiology (ESC). Eur Heart J. 2016;37(36):2768-801.

3. Mac MJ, Packer M, et al. Angiotensin- Neprilysin inhibition versus Enalapril in heart failure. N Engl J Med. 2014;371:993-1004.

4. Herrmann J, Lerman A, et al. Evaluation and Mangement of patients with heart failure and Cancer: cardio-oncology. Mayo Clin Proc. 2014;89(9):1287-306.

5. Plana JC, Galderisi M, et al. Expert consensus for multimodality imaging evaluation of adult patients during and after cancer therapy: a report from the American Society of Echocardiography and the European Association of Cardiovascular Imaging. J Am Soc Echocardiogr. 2014 Sep;27(9):911-39.

6. Chandra A, et al. Effects of Sacubitril/valsartan on Phisycal and social activity limitations in patients with heart failure. A secundary analysis of the PARADI GM-HF trial. JAMA Cardiol. 2018;3(6):498-506.

7. Porcile $R$ et al. Remodelación inversa del miocardio y reducción de marcadores inflamatorios en pacientes con insuficiencia cardíaca tratada con sacubitrilo/valsartán Insuficiencia Cardíaca, vol. 13, núm. 3, 2018.

8. Kang DH, Park SJ, Shin SH, Hong GR, Lee S, Kim MS, et al. Angiotensin receptor Neprilysin inhibitor for functional mitral regurgitation. Circulation. 2019;139(11):1354-65. 
9. Mullens W, Martens P. Sacubitril/valsartan to reduce secondary mitral regurgitation. Refinement of GuidelineDirected medical therapy? Circulation. 2019;139:1366-70.

10. Christina E. Sheppard, Maria Anwar. The use of sacubitril/valsartan in Anthracycline-induced cardiomyopathy: a mini case series. J Oncol Pharm Pract. 2019;25(5):1231-4.

11. Morris $\mathrm{K}$, et al. Novel use of valsartan-sacubitril as treatment for trastuzumab induced cardiomyopathy. J Am Coll Cardiol. 2019;73(9) Supplement 1:1097.

12. Camilli M, Del Buono M, Crea F, Minotti G. Acute heart failure 29 years after treatment for childhood Cancer. JACC. 2020;2(2):316-9.

13. Gregorietti V, et al. Use of sacubitril valsartan in heart failure due to postchemotherapy symptomatic ventricular dysfunction. Eur J Heart Fail. 2018;20(Suppl. S1):562.

14. Martín-Garcia A, López-Fernández T, et al. Effectiveness of sacubitrilvalsartan in cancer patients with heart failure. ESC Heart Fail. 2020;7(2):1-5.

\section{Publisher's Note}

Springer Nature remains neutral with regard to jurisdictional claims in published maps and institutional affiliations.

Ready to submit your research? Choose BMC and benefit from:

- fast, convenient online submission

- thorough peer review by experienced researchers in your field

- rapid publication on acceptance

- support for research data, including large and complex data types

- gold Open Access which fosters wider collaboration and increased citations

- maximum visibility for your research: over $100 \mathrm{M}$ website views per year

At BMC, research is always in progress.

Learn more biomedcentral.com/submissions 